\title{
An account of Boeschian cooperative behaviour
}

Blomberg, Olle

Published in:

Collective Agency and Cooperation in Natural and Artificial Systems

DOI:

10.1007/978-3-319-15515-9_9

Publication date:

2015

Document version

Early version, also known as pre-print

Citation for published version (APA):

Blomberg, O. (2015). An account of Boeschian cooperative behaviour. In C. Misselhorn (Ed.), Collective Agency and Cooperation in Natural and Artificial Systems: Explanation, Implementation and Simulation (pp. 169-184). Springer. Philosophical Studies Series Vol. 122 https://doi.org/10.1007/978-3-319-15515-9_9 


\title{
An Account of Boeschian Cooperative Behavior
}

\author{
Olle Blomberg
}

\begin{abstract}
Philosophical accounts of joint action are often prefaced by the observation that there are two different senses in which several agents can intentionally perform an action $\Phi$, such as go for a walk or capture the prey. They might intentionally $\Phi$ together, as a collective, or they might intentionally $\Phi$ in parallel, where $\Phi$ is distributively assigned to the agents, considered as a set of individuals. The accounts are supposed to capture what characterises activities in which several agents intentionally $\Phi$ collectively rather than distributively, in which they go for a walk together or capture the prey together. This dualism between joint and parallel action also crops up outside philosophy. For instance, it has been brought into a debate about whether or not group hunting among chimpanzees is a form of joint cooperative hunting. I do not take sides in this debate, but offer an account of a form of joint action that falls short of what most philosophers take to be required for genuine joint action, but which is not merely parallel activity. This shows that the dualism between the genuinely joint and the merely parallel is false. I offer my account as an explication of an influential definition of "cooperative behaviour" given by the primatologists Christophe and Hedwig Boesch.
\end{abstract}

Key words: joint action, cooperative behaviour, common goal, false dualism, chimpanzee group hunting

\section{The Dualism of the Joint and the Parallel}

Accounts of joint action are often prefaced by the observation that there are two different senses in which several agents can intentionally perform an action $\Phi$. They might intentionally $\Phi$ together, as a collective, or they might intentionally $\Phi$ in parallel, where $\Phi$ is distributively assigned to the agents, considered as a set of individuals. The accounts are supposed to capture what characterises activities in which several agents do intentionally $\Phi$ collectively rather than distributively (Gilbert 2009, 168; Kutz 2000,1-2; Bratman 2009, 150-1). An account of intentional joint action should thus illuminate how the agency of two friends going for a walk together is different from that of two strangers walking down the street in parallel, each trying to avoid colliding with the other while they are independently walking toward the same destination (Bratman 2009; Gilbert 2009). Often, the difference is couched in terms of the presence or absence of a "shared intention". If the agents have a shared intention to $\Phi$, then the $\Phi$-ing that ensues is an intentional joint action. While it is sometimes acknowledged that there may be many different kinds of shared intention, it is taken for granted that an activity involving several agents is either a genuine form of joint action, or it merely involves coordinated actions performed in parallel.

This dualism between joint and parallel action also crops up outside philosophy. For instance, it has been brought into a debate about whether or not the group hunting in some chimpanzee populations is a form of joint cooperative hunting. Chimpanzees in Taï National Park in the Ivory Coast frequently hunt colobus monkeys, who reside in the canopy of the trees. Christophe Boesch argues that in these hunts, groups of typically 3-5 members perform coordinated hunts toward the goal that they capture the prey, where group members adopt different roles during the hunt (Boesch and Boesch 1989; Boesch 2002; Boesch 2005). One chimpanzee, the driver, gets the prey moving in certain direction. Blockers take up positions that force the prey to flee in a certain direction, where an ambusher might be waiting in a tree. Along the flight, chasers may also follow the prey on the ground to then climb up the tree

Olle Blomberg

Center for Subjectivity Research, Department of Media, Cognition

and Communication, University of Copenhagen, Copenhagen, Denmark

e-mail: olle.blomberg@gmail.com 
that the prey is occupying. Here, Boesch draws an analogy between how the chimpanzees' success in capturing the prey depends on the contribution of each group member and how a football team's win in a game depends on the contribution of each player:

Like in a team of soccer players, individuals react opportunistically to the present situation while taking in account the shared goal of the team. Some players will rarely make a goal, like defenders and goalies, but the success of the team will critically depend upon their contribution. This is very reminiscent to group hunting in chimpanzees where synchronisation of different coordinated roles, role reversal, and performance of less successful roles favour the realisation of the joint goal. (Boesch 2005, 692)

Boesch (1994) also argues that how the meat of the captured prey ends up divided among the chimpanzees is determined primarily by the participation and contribution of each in the hunt (as well as by dominance rank and age).

Michael Tomasello and his colleagues have suggested that a competing explanation of the Taï chimpanzees' hunting behaviour is more plausible (Tomasello et al. 2005, 685). They argue that what looks like the coordinated performance of a team is actually just the emergent product of each chimpanzee trying to maximise the chance of capturing the monkey for itself:

Normally, one individual begins the chase, and others scramble to the monkey's possible escape routes. The individual who actually captures the monkey gets the most meat, but because the captor cannot dominate the carcass on his own all participants (and many bystanders) usually get at least some meat as well [...]. The social and cognitive processes involved here are probably fairly simple: each individual is attempting to capture the monkey on its own, and so each takes into account the behaviour of the other chimpanzees as they are pursuing this individual goal. [...] The short story is thus that chimpanzees have no joint goal that "we" capture [the monkey] and share it, helping the other in his role as needed, and no sense of commitment [...]. (Tomasello and Hamann 2012, 8)

Tomasello $(2014,190)$ also argues for an alternative interpretation of Boesch's data on how the meat is shared after a successful hunt. According to Tomasello, the main factor that determines who gets a share is the chimpanzees' proximity to the kill rather than their contribution to the hunt.

In contrast, Tomasello and colleagues argue that human beings, including 3-year-olds, routinely engage in what he and Katharina Hamann call "true collaboration":

[I]t is true collaboration when in addition to [participants] being mutually responsive to one another [...], two key characteristics are present: (a) the participants have a joint goal or intention in the sense that they each have the goal or intention that we (in mutual knowledge) do X together; and (b) the participants coordinate their roles-their plans and sub-plans of action-including helping the other in her role as needed. (Tomasello and Hamann 2012, 2)

The notion of 'joint goal' is a goal that an individual agent has, but which concerns a collective activity, such as "that we capture the prey" or "that we go for a walk" (see Pacherie 2013, 1821-22). According to Michael Bratman (1992), whose work on "shared cooperative activity" Tomasello and Hamann draw on, each participant intends a joint goal "that we $\Phi$ ", where $\Phi$ is a type of collective activity. To avoid a circularity, it cannot be required that the notion of collective activity that figures in the agents' intentions is that of "true collaboration" (in Tomasello and Hamann's case) or that of "shared cooperative activity" (in Bratman's case). ${ }^{1}$ On Tomasello's interpretation, the chimpanzees that are involved in a group hunt do not each intend such a joint goal. Rather, each merely tries to capture the monkey for itself; each has the goal "that I capture the monkey for myself". Boesch, on the other hand, argues that the available evidence favours that each chimpanzee has the joint goal "that we capture the monkey".

I will not take sides in this dispute. I merely want to unearth the dualism that underpins it. Both sides assume that chimpanzee group hunting is either cognitively demanding "true collaboration" or merely cognitively unsophisticated coordination of hunters each pursuing an individualistic goal. ${ }^{2} \mathrm{My}$ aim in this chapter is to show that this dualism, which shows up in both philosophical and scientific discussions about joint action and cooperation, is false. (Of course, even if the dualism is false, Boesch or Tomasello may still be right about what characterises group hunting among the chimpanzees in Taï National Park.) While statements that several agents $\Phi$ together can either be given a collective interpretation or a distributive interpretation, this semantic dualism does not reflect an underlying dualism of socio-psychological kinds.

I will show that the dualism is false by giving an account of a kind of joint action that is neither true collaboration, nor merely a set of coordinated pursuits of individualistic goals. My starting point will be an operational definition of

1 For a discussion of this circularity problem and why it needs to be avoided, see (Petersson 2007).

2 To be fair, Boesch now seems to be more agnostic regarding what is required for group hunting to be cooperative. See (C. Boesch 2012, 92-93), where he refers to several accounts of joint action, including Steve Butterfill's (2012) account of 'shared goals'. 
cooperative behaviour given by Christophe and Hedwig Boesch (1989). The Boesches there define the cooperative behaviour simply as "two or more individuals acting together to achieve a common goal" $(1989,550){ }^{3}$ The definition tells us almost nothing about what the cognitive or conceptual prerequisites for participating in cooperative behaviour are. In addition, the definition contains a core notion that is never explicated, namely that of a 'common goal'.

The mere fact that two agents happen to have a common goal (whatever the criteria for that are) does not itself facilitate cooperation or coordinated action toward it. My account will take the form of a set of sufficient conditions that specifies a pattern of psychological states and relations among participants that could enable this fact to facilitate coordinated action directed to the common goal. This account is given in the next section. In section 3 , I then consider what cognitive and conceptual requirements an agent needs to meet in order to participate in this form of joint action. In section 4, I then comment on the notion of agent-neutral goals, which enables my account to occupy a middle-ground between true collaboration and mere parallel activity. Finally, in section 5, I consider what sorts of empirical evidence that could license us to infer that some observed behaviour is an instance of the kind of joint action I give an account of.

\section{Having a Common Goal and Acting Jointly}

The term 'goal' can be used to refer to a state of affairs or an outcome $O$ toward which an action is directed, or to the content $G$ of a goal-directed state of an agent. The term 'common goal' can thus be used to refer to a relation between several actions or to refer to a relation between several agents. These uses are of course intimately related. Several agents' actions may have a common goal - that is, be directed to a single outcome $O$-in virtue of the agents having a common goal $G$, given that $O$ would satisfy $G$ if it were brought about. Plausibly, actions can be goaldirected in virtue of other kinds of facts though. Perhaps the behaviour of several insects can be directed to a single outcome, but not in virtue of the insects being in certain goal-directed states. Consider the feeding behaviour of a family of Stegodyphus spiders. If a large prey such as a fly lands in the family's web, then this creates vibrations in the web. In response to the vibrations, each spider independently approaches the prey (Ward and Enders 1985; quoted in Brosnan et al. 2010, 2701). When the prey is reached, each then-again, independently of each other-starts to pull the prey toward the communal nest where it is digested and consumed by all. No spider could on its own catch and transport the large prey. In this case, the function of each spider's behaviour may be to bring it about that the prey is collectively brought to the nest, even if there is no goal-directed state that represents this outcome. If this is actually the evolutionary function of the spiders' behaviour, then it is arguably an interesting case of a form of collective behaviour. However, I will in the following use 'goal' to refer to the content of a goal-directed state and refer to the goal of an action as the 'outcome' that the action is directed to. Furthermore, I will assume that an action directed to $O$ is so directed partly in virtue of it being controlled by goal-directed state that is satisfied by $O$. An agent that is in a goal-directed state with content $G$ which is satisfied by an outcome $O$ is said to aim at $G$.

I take a goal-directed state to either be (i) a mental state with a world-to-mind direction of fit such as a desire or an intention, or (ii) the combination of a desire or intention and a means-end belief, where the means is the goal toward which the agent's action is directed. An example of (ii) is the following: I have the desire to eat and the means-end belief that if I cook dinner, then I will be able to eat. This combination may cause me to go into the kitchen, look into the fridge, put some ingredients in a pan, and so on, that is, to perform a series of actions that are all directed toward the goal of cooking dinner. The outcome that I cook dinner may not be represented by a state with a world-to-mind direction of fit; there is a state with world-to-mind direction of fit involved (the desire to eat), but it does not represent me cooking dinner. In the process of deliberating about what to do, perhaps I form or acquire an "instrumental desire" or sub-intention to cook dinner (see Sober and Wilson 1998, 217). However, this need not be the case. As Kim Sterelny (2003) points out, "[w]e can trade talk of instrumental goals for talk of beliefs", and thus "convert intentional explanations that mention instrumental goals into intentional explanations that mention only ultimate goals." (p. 88) A creature could have only one desire-say, the desire to survive-but still perform actions and activities directed to many different goals.

3 This definition has also been adopted by other researchers in both comparative and developmental psychology (see Chalmeau and Gallo 1995; Naderi et al. 2001; Brinck and Gärdenfors 2003; Brownell, Ramani, and Zerwas 2006). 
For the notion a common goal to help us distinguish joint action from coordinated activity, the agents' actions must be directed to a single outcome. There must be single outcome that satisfies the goal of each agent. Consider John Searle's (1990) example of several individuals running to take shelter from the rain. The goal of the running of each individual can be specified by the sentence "that I reach the shelter", so there is sense in which they have the same goal: each has a goal with the same character. Nevertheless, each individual aims at a distinct goal, and the conditions of satisfaction of their intentions are different. The intention of one of the runners is satisfied if he reaches the shelter while the intention of another is satisfied if she reaches the shelter, and so on. ${ }^{4}$ The term 'common goal' is sometimes used to refer to a situation where the same token object is the target of several agents' goal-directed actions. ${ }^{5}$ For instance, Chalmeau and Gallo talk about the common goal of the chimpanzees studied by the Boesches as being simply "the prey" (1995, 103). Similarly, Brinck and Gärdenfors talk of actual objects in the chimpanzees' environment as their goals, such as "water to drink, food to be had, or an antagonist to fight" (2003, 485). Perhaps these are just elliptical ways of referring to states of affairs such as "that we capture the prey" or "that we fight the antagonist", but it is important to keep in mind that goals are states of affairs rather than target objects, or else the notion of a common goal' will not help us to distinguish cooperation from competition. If Alphonse and Amanda are each reaching for a piece of fruit, then their actions have the same target object, but they do not have a common goal. Alphonse's goal is to snatch the fruit for only him to eat; Amanda's is to snatch the fruit for only her to eat.

For the notion of common goal to help us understand joint action and cooperative behaviour, we must take several agents to have a common goal if the conditions of satisfaction of their actions or goal-directed states are the same. There must be a single token outcome or state of affairs that each agent aims at. If brought about, the state of affairs would satisfy the goal-directed state of each.

(1) Single outcome condition: There is a single outcome $O$ that satisfies a goal $G_{1}, G_{2}, \ldots, G_{m}$ of each agent $A_{1}, A_{2}$, ..., $A_{m}$.

Note that this condition that there is a single outcome that satisfies a goal of each agent is not meant to exclude that there may be multiple such token outcomes. It merely implies that at least $O$ is such a token outcome. Why not just say that there is a goal that each agent aims at? The reason why there is no goal that each runner is aiming at is that each runner is aiming at distinct goal after all, the content the goal-directed state that each is in is distinct; it is just that these goals have the same character. Many philosophers, such as John Searle (1983) for example, take the specification of the conditions of satisfaction for a mental state to also be a specification of its content. Several agents would then have a common goal if their goal-directed states had the same content. In section 4 , I argue that there are actually reasons for taking not only the content of a mental state to determine its conditions of satisfaction. The state's mode, that is, the kind of state it is, also partly determines the conditions of satisfaction. But even if we accept Searle's view, we want to be able to say that two agents have different goals even if these goals have identical conditions of satisfaction. This is because it makes sense to individuate the goals of agents not only with respect to the states of affairs that satisfy them but also with respect to how those states of affairs are represented, with respect to under what aspects they are represented. If I intend to kill Batman and intend to kill Bruce Wayne, but am unaware that Bruce Wayne is Batman, then I have two rather than one goal. This shows that goals should in general be specified with respect to aspects and not only their extensions. However, in the case of joint action, agents could arguably represent what they are aiming at under different aspects but still have a goal in common. For example, suppose Ali's goal is that the monkey who rustles the leaves is captured and Kendo's goal is that the monkey who casts the shadow is captured, then Ali and Kendo could still engage in a joint action directed at the outcome that the monkey is caught.

That (1) holds does not itself facilitate cooperation. For the fact that there is a single outcome $O$ that satisfies each agent's goal to play a role in facilitating and coordinating joint action directed to $O$, each agent should also believe that (1) holds.

(2) Doxastic single outcome condition: $A_{1}, A_{2}, \ldots, A_{m}$ each believes that (1).

4 Searle $(1990,402-3)$ uses the term "common goal" to talk about the relationship between the runners' goals in this case. Cohen, Levesque, and Smith $(1997,96)$ and Miller $(1986,133)$ also use the term in this way.

5 On the distinction between goal and target object, see Jacob $(2012,209)$. 
Note that in order for (2) to be satisfied, it is not sufficient that there is single outcome $O$ such that it satisfies the goals $G_{1}, G_{2}, \ldots, G_{m}$ that each agent believes they and the others have. For (2) to be satisfied, each agent must also be aware of the fact that $O$ is a single outcome that satisfies all the goals $G_{1}, G_{2}, \ldots, G_{m}$. The condition therefore helps rule out the case where Ali's goal is that the monkey who rustles the leaves is caught, Kendo's goal is that monkey who casts the shadow is caught, but Ali and Kendo each falsely believes that these are two distinct monkeys, when in fact there is only one monkey who both rustles the leaves and casts the shadow. It is worth noting here that most existing accounts of joint action do not rule out such Frege-style cases and that they arguably need to incorporate a condition similar to $(2){ }^{6}$

Recall that according to the Boesches' definition, several individuals are behaving cooperatively when they are "acting together to achieve a common goal" (my emphasis). But conditions (1) and (2) could be satisfied even if $O$ is such that it cannot be brought about by more than one individual. Suppose several agents are inside a room, each with the goal to open the door. Each also believes that the goal of each will be satisfied if the door is opened. However, the small door handle cannot be operated by more than one person simultaneously, and each agent knows this. In this case, the fact that conditions (1) and (2) are satisfied doesn't put the agents in a position vis-à-vis each other to coordinate their actions to open the door. Here, Kaarlo Miller and Raimo Tuomela's notion of a "dividable" goal is useful: "Goal P of an agent $\mathrm{x}$ is dividable if and only if there will, or at least can, be parts or shares for at least one other agent to bring about (or sustain) P." (Miller and Tuomela 2013, 6; see also Butterfill 2013, 849-50) The goal of each agent in the room is not dividable. Likewise, the goal of a chimpanzee that is trying to capture the monkey for itself does not have a dividable goal. However, a chimpanzee who intends "that we capture the monkey together" does have a dividable goal, as does a chimpanzee who is simply trying "to capture the monkey" (assuming that the satisfaction of this goal is compatible with the contributions of other agents). What is crucial is not whether the goal of each is dividable, but that each agent believes that the goal of each is dividable:

(3) Doxastic dividable goal condition: Each agent $A_{1}, A_{2}, \ldots, A_{m}$ believes that the goals $G_{1}, G_{2}, \ldots, G_{m}$ are dividable.

Finally, each agent that participates in the joint action expects that the others also participate:

(4) Doxastic action condition: In virtue of their beliefs specified in (1) and (2), each agent $A_{1}, A_{2}, \ldots, A_{m}$ believes that the the others has performed, is performing or will perform an action directed to $O$ in order to achieve their goal $G_{1}, G_{2}, \ldots, G_{m}$.

If these belief states and goal-directed states of the agents cause them to perform actions directed to $O$, then I submit that these actions constitute a form of joint action. Note that this account does not exclude that joint action may include elements of coercion and manipulation. But given that conditions (1)-(4) are satisfied, then coercion or manipulation of others are unlikely to be of benefit to a participating agent.

In the next section, I argue that this type of joint action is only modestly cognitively demanding. In particular, it does not require agents to be able to appreciate that others have different perspectives on the world. In the section 4, I defend the claim that this type of joint action occupies a middle-ground between "true collaboration" and mere coordinated individualistic pursuits.

\section{Cognitive and Conceptual Demands}

Conditions (1)-(4) are relatively cognitively and conceptually undemanding. To participate in joint action that is caused by the belief states and goal-directed states defined by these conditions, agents need not be able to attribute beliefs to other agents. But they must be able to attribute goals to others. Non-human primates seem to fit this sociocognitive profile. At least, chimpanzees appear to be sensitive to the goal-directness of others' actions (Call et al. 2004; Call and Tomasello 2008). However, note that the fact that they can recognise the goals that another's action is directed toward does not imply that they can attribute a goal to the agent of that action. Instead, they may simply

6 In Blomberg (forthcoming), I show that this is at least the case when it comes to Steve Butterfill's (2012) account of shared goals. 
represent the goals as states of affairs toward which the actions are pulled, or represent them as the function of the bodily movements in question (see Csibra and Gergely 2007; Butterfill and Apperly 2013). In other words, recognising the goals that actions are directed toward does not necessarily require metarepresentational capacities. One can recognise a goal that another agent's action is directed toward without representing that goal as something that is represented by the other agent (see Butterfill (2012) for an account of joint action that doesn't require that agents are able to attribute goals to other agents, but only to the actions of others). Nevertheless, it is possible that chimpanzees have a mentalistic understanding of goal-directedness, even if they do not have a mentalistic understanding of beliefs. With such a partial understanding of other minds, they could make sense of actions in terms of partially subjective motivating reasons for action, in terms of desires or intentions that they attribute to others in combination with facts about the world (thus, they draw on their own beliefs about the world). ${ }^{7}$ No study has hitherto been able to show that non-human primates are able to attribute beliefs to others, but my account does not require that participants have this ability.

The account also requires that agents have general capacities for reasoning about how several causal contributions may generate a combined effect. Exactly what is required will of course depend on the task that the participants are facing. Clearly, many types of agents have such capacities, including chimpanzees (see e.g. Seed and Call 2009).

As I have noted, Tomasello and Hamann's "true collaboration" as well as Bratman's "shared cooperative activity" requires that participants have joint goals, goals "that we (in mutual knowledge) do X together" or "that we $\Phi$ ". Is this conceptually and cognitively demanding? If mutual knowledge requires a concept of belief (see Glüer and Pagin 2003; Tollefsen 2005), then the former notion appears to be beyond what non-human primates could intend. However, there are arguably weaker notions of collective activity that could figure in the content of the agents' intentions, so a requirement that each agent intends "that we $\Phi$ " need not be very conceptually demanding (see Petersson 2007). To illustrate, we can conceptualise the activity of a family of Stegodyphus spiders without conceiving of them as having any mutual knowledge or goal-directed states. Such a weak concept of collective activity or joint action may figure in the content of the intentions of those who engage in "shared cooperative activity" or similar robust forms of joint action. Nevertheless, the account I have given does not even require that agents have such a weak concept of joint action.

\section{The Middle-Ground: Agent-Neutral Goals}

The kind of joint action that I have specified in section 2 occupies a middle-ground between "true collaboration" and mere parallel activity because conditions (1)-(4) can be satisfied even if none of $G_{1}, G_{2}, \ldots, G_{m}$ is a joint goal. A goal may be neither "joint" nor be exclusively about an individual's own agency. ${ }^{8}$

Consider the case of two individual agents who go for a walk together. They can do this in a way which is neither like the friends going for a walk together, nor like two strangers who each go for a walk in parallel. Suppose that Ann and Bob are colleagues who are taking part in a workplace pedometer challenge. Each of them has a pedometer-a step-counting device-that displays the sum of the total number of steps they have taken. Ann and Bob each intends that the total number of steps reaches 10,000 (not that they take 10,000 steps). Their actions are to some extent interdependent. If one of them sees that the other isn't going to walk at all, then they will rescind their intention. One of them cannot take 10,000 steps on their own in time they have at their disposal. If one of them sees that the other is walking a lot, then they may themselves take fewer steps since their intention is likely to be satisfied anyway. Here, if all of conditions (1) to (4) are satisfied and if Ann and Bob's belief states and goal-directed states cause them to take 10,000 steps, then arguably, they take 10,000 steps together by performing a joint action.

Both Ann's and Bob's goal is dividable here without being a "we"-goal. These goals are agent-neutral in the sense that they are compatible with the possibility that the other agent contributes to its achievement, but this contribution is not itself part of what the agent herself aims at. However, it also looks like these goals are compatible with the absence of a contribution from the agent herself. Ann's goal would, it seems, be satisfied even if she was never moved to take a single step if Bob somehow managed to walk 10,000 steps on his own. If that is right, then it becomes somewhat mysterious why condition (4) would be satisfied. After all, it seems that such agent-neutral goals

7 This would be akin to what Perner and Roessler $(2010,205)$ call the "the hybrid account of children's conception of intentional action". 8 My account of joint action is not the only one that does not require that the actions that constitute a joint action is directed to a collective activity. Other such accounts include Pacherie and Dokic (2006, 110), Butterfill (2012) and Miller (2001). 
would be satisfied even if the agents never get involved in the action so to speak. Why then would each agent expect that the others have performed, are performing or will perform actions directed to $O$ given that their goals are agentneutral in this sense?

Given a certain view of the content of intentions, this question doesn't arise if the goal-directed states that Ann and Bob are in are intentions. ${ }^{9}$ According to this view, the agent's self, in the form of the indexical 'I', as well as the causal efficacy of her intention figures constitutively in the specification of the content of an intention. For example, according to Searle, the content of an intention to raise my arm that I have prior to raising it is "[that] I perform the action of raising my arm by way of carrying out this intention" (1983, 92). Ann and Bob's goal-directed states could not on this view be intentions but would have to be some other type of goal-directed states. ${ }^{10}$ Still, we want their goal-directed states to play some role in causing and coordinating the agents' activities that are directed to bringing about the goal.

Now, we can avoid this difficulty if we drop the assumption that it is only that content of a goal-directed state that determines its conditions of satisfaction. The conditions are arguably not determined solely be features that are internal to the content of the state in question. To be specific, the conditions of satisfaction for an intention or other goal-directed state is also in part fixed by its mode, that is, by what makes it the kind of goal-directed state that it is. ${ }^{11}$ We can think of a mental state's mode in functional terms, defined by its role in the agent's psychic economy, including its role in causing and coordinating action.

The causal self-reflexivity that Searle places in the content of an intention is arguably part of what makes this goal-directed state into an intention rather than, say, a different state with world-to-mind direction of fit such as a hope or a wish. This suggests that the causal self-reflexivity is not part of the content of an intention, but that it is determined by what the function of intention is. Arguably, what is intended does not include this causal selfreflexivity. I do not intend that "I perform the action of raising my arm by way of carrying out this intention", but rather simply "to raise my arm". Nevertheless, since the mode in which I represent this is the mode of an intention, the action will only be successful if it is appropriately caused and coordinated by the intention in question. The role of the agent's own agency may thus merely be implicitly represented in the cognitive system's architecture. The goal-directed state that controls the agent's movements as she, say, approaches a table that she wants to move, could thus fail to fulfil its function if the state wasn't involved in bringing about the outcome that satisfied her goal "that the table is moved". However, there is no reason to think that the state would fail to fulfil its function if other agents were also playing a causal role in bringing about the satisfaction of the goal.

One might suspect in response to this that an agent-neutral goal is just a disguised "me"- or "we"-goal. ${ }^{12}$ This is a reasonable suspicion since the conditions of satisfaction remains the same whether they are completely determined by the content of the goal-directed state or whether they are in part also determined by the state's mode. However, this is not merely a terminological move. First, the fact that the conditions of satisfaction includes that condition that the agent herself brings about $O$, possibly with help of the contributions of others, then does not require that the agent has the ability to think of herself as an agent or to think of herself as as acting with others. The role of the self as an agent can merely be implicit in the mode of the goal-directed state ${ }^{13}$ Secondly, having a goal that allows for the contributions of others is not equivalent to having the goal that others contribute, that we do it. If Ann intends that 10,000 steps is taken, she will adjust her activities in light of what she believes or expects about Bob's activities, but she doesn't intend that Bob contributes.

Consider several agents who are out hunting an arboreal prey. Suppose that each agent in the group has the goal "that the prey is captured" or "to capture the prey", where the satisfaction of this goal is compatible with the involvement of others. Furthermore, each performs appropriate actions directed to the outcome that they prey is caught, and they do this in virtue of their beliefs that this single outcome satisfies a goal of each and their belief that

9 Nor does the question arise if Ann's and Bob's goal was "that we take 10,000 steps". After all, each of them takes herself or himself to be a member of the "we" that the goal concerns.

10 On Searle's view, my condition (1) will never be satisfied by goals that agents have in virtue of what they intend. His view implies that there is never a single outcome that satisfies the intention of each. The conditions of satisfaction for our ordinary intentions will never be the same.

11 Björn Petersson (2015) makes this point in the context of a discussion of Bratman's account of shared cooperative activity. Petersson draws on the work of François Recanati (e.g. 2007).

12 Thanks to an anonymous reviewer for raising this worry.

13 See Sober and Wilson $(1998,213-17)$ for a related discussion about the possibility of "general and impersonal desires" and the evolutionary benefits of self-directed desires. 
their goals are dividable. Arguably, their hunting the prey would now be a kind of joint action. If the prey is captured, then they capture it together by performing a joint hunt.

What I am suggesting is that perhaps this is the best way of conceptualising chimpanzee group hunting. It would on this view be part of the function of the chimpanzees' goal-directed states to facilitate that each agent contributes to the prey being caught (within the context of the hunting activity of the group). However, each agent need not explicitly intend that they, individually or collectively, catch the prey. Of course, this is not to deny that each agent has an interest in getting a share of the prey if one of the agents finally reaches or intercepts the prey. Otherwise they would not have the goal "that the prey is captured". This suggestion is of course hostage to empirical fortune. If Tomasello and colleagues are correct that what determines a chimpanzees' share of the spoils is simply its proximity to the kill, then this would of course be defeasible evidence for the view that each chimpanzee has the goal "that I capture the prey", where this is compatible with the contributions of others. Here, I leave this empirical issue be.

\section{Empirical Tractability}

My aim in this section is to say something about how conditions (1)-(4) are related to empirical studies of performance on tasks that require agents to cooperate and coordinate their actions. Whether or not we should claim that a multi-agent activity is coordinated by the goal-directed states and belief states specified by conditions (1)-(4) will depend on whether those states figure in our best psychological explanation of how the activity came about. This issue is one of inference to the best explanation, so we should not expect or demand a fixed set of behavioural criteria that can be used to decisively determine whether those states are present or not. The best one can hope for is a set of relevant constraints and factors that can be used to judge whether an inference to their presence is justified or not.

One source of evidence is constraints given by the cognitive and conceptual capacities of the agents involved, as suggested in section 3. Another source of evidence concerns whether two or more individuals reliably achieve an outcome that is desired by each but which can only be brought about if they coordinate their actions. In such a case, the performance of the subtask of each comes to nothing unless the other also performs his or her subtask. If one can observe that an individual only performs its own subtask (or is more likely to perform it, or performs it at higher rate) when the other individual is likely to carry out its subtask (such as only when the other individual is present for example, or only when the other individual is facing in the relevant direction) then we can infer that this individual has some understanding of the role the other plays for successful task completion. On the basis of this line of reasoning, primatologists, comparative psychologists, and developmental psychologists have tested whether various types of agents are able to coordinate their actions to achieve a common goal.

The following experimental setup from a study by Alicia Melis et al. (2006) is representative. Melis et al. tested whether chimpanzees were able to rationally judge when to recruit a collaborator in order to retain food. Each subject was presented with a platform baited with food that was placed behind a railing. A rope was threaded through metal loops on the platform, with both ends of the rope extending through the railing into the test room that the subject was released into. If a subject only pulled on one rope end in order to drag the food-baited platform toward the railing, then the rope would unthread through the metal loops and come loose from the platform (and thus make it impossible to retrieve the food). In order to get the platform to get closer to the railing, either both ends had to be pulled at the same time or one end had to be pulled while the other was held steady. In an adjacent locked room another chimpanzee, a potential co-operator, was waiting. By removing a wooden peg, a test subject could release the other chimpanzee into the test room. Melis et al. were interested in how the decision of a subject to release or not to release the other chimpanzee depended on whether it was physically possible for the subject to retrieve the food from the platform or not.

There were two conditions in this experiment: the collaboration condition and the solo condition. In the collaboration condition, the ends of the rope were placed three metres apart so that it was impossible for the subject to hold or pull both ends of the rope at the same time. Hence, to retrieve the food on the platform in the collaboration condition, the subject would have to release the collaborator into the test room. Then each could pull one rope end and together drag the platform toward the railing. In the solo condition, the ends of the rope were placed fifty-five centimetres apart, so that it was possible for the subject to pull both rope ends at the same time. The subject could thus acquire all the food for herself without having to share half of it with the collaborator. The result was that seven of the eight chimpanzee subjects released the collaborator significantly more often in the collaboration condition than 
in the solo condition. Melis et al. took this to show that the chimpanzees were sensitive to the fact that both their own contribution and the contribution of the collaborator were required for successful food retrieval.

This experiment gives an either/or measure of subjects' understanding of whether or not a situation calls for cooperation: the chimpanzee can either release the potential partner or choose not to. In other experiments, subjects are repeatedly trying to do something either alone or together with a partner. This allows one to compare the rate at which subjects try to achieve a goal (such as retrieving food) without and with a partner. If a task requires the contribution of a partner and there is a significant difference in the rate of attempts between when the partner is absent and when the partner is present, then this suggests that the individuals are monitoring each other's activity and modulating their activity in light of what the other is doing (see Chalmeau and Gallo 1995; Chalmeau 1994; Visalberghi, Quarantotti, and Tranchida 2000).

If a subject clearly shows sensitivity to the fact that a task requires another's contribution, then any interpretation that construes the behaviour of these agents as rational will involve attribution of a dividable goal to at least one agent (the subject in Melis et al.'s task). Purely individualistic goals-goals "that I bring about $O$ on my own"cannot be satisfied if the agent knows that bringing about $O$ is impossible without the contribution of another agent. It may of course be the case that the goal the agent has in common with another agent, say the goal "to bring the platform to the railing", is one that she only has in virtue of an instrumental desire formed in light of her ultimate desire "to eat all food myself". The higher-level goal that she has in virtue of this ultimate desire will then not be shared with another agent. ${ }^{14}$

Note that the experiments confound the situation where subjects have a common goal but fail to grasp that there is an opportunity to benefit from coordinated action, and the situation where they do have the causal understanding required to benefit from coordinated action but lack a common goal. The capacity to have dividable goals and to recognise that one has a goal in common with another agent can thus be masked by failure to meet other performance requirements of the task. In particular, the task may require a quite sophisticated understanding of causal relationships for an agent to understand that the contribution of another agent can help him or her to achieve the goal. But if a subject only acts in concert with a partner, or only acts when a partner is likely to contribute, then inferring that the subject has the capacity to participate in a form of joint action with another seems to be justified (that is, that the subject is able to appreciate that he and another agent have a common goal and that it is more likely that the goal is achieved if both perform their contributions).

However, note that apparently purposive coordination may be the result of the fact that the agents are embedded in the same environment at the same time, and thus presented with similar constraints and opportunities for action. This may accidentally lead to similar actions being performed roughly at the same time toward the same target object. But we cannot conclude from the fact that coordination is merely accidental that the agents do not have a common goal. Plausibly, some multi-agent activities may be coordinated in virtue of agents typically having agentneutral goals and high social tolerance, so that they are able to act in parallel in close proximity to each other, and thereby be exposed to the same action constraints and opportunities, potentially leading to them to perform actions directed to a single outcome $O$ (see Petit et al. (1992) on "coproduction"). However, this would not amount their actions constituting a joint action that is caused by the states defined by conditions (1)-(4).

\section{Conclusion}

The starting point for the account of joint action that I have given in this chapter is an influential definition according to which 'cooperative behaviour' consists of "two or more individuals acting together to achieve a common goal" (Boesch and Boesch 1989, 550). The account specifies an inter-agential pattern of goal-directed states and belief states that can facilitate the coordination of several agents' actions with respect to the common goal. Here, several agents have a common goal if there is a single outcome that satisfies a goal of each agent (single outcome condition) and each agent believes that this is the case (doxastic single outcome condition). For their having a common goal to play a role in enabling coordinated action directed to the single outcome that satisfies their goals, each must also believe that the goal of each is compatible with the involvement of the others (doxastic dividable goal condition).

14 Note that I have not considered the issue of how agents share the spoils of their joint action. The account I have given concerning coordination of action toward a common goal, it does not say anything about how agents act once the goal has been achieved. 
Furthermore, in virtue of these beliefs, each must also believe that each of the others has performed, is performing or will perform actions toward the single outcome in order achieve their goal (doxastic action condition).

This account differs from Tomasello and Hamann's account of "true collaboration" and Bratman's account of "shared cooperative activity" in several respects. First, it is relatively cognitively undemanding in comparison to these accounts. In particular, the account doesn't require that participants represent beliefs and understand that others can have a different cognitive perspective on the world. Secondly, the account doesn't require that each agent has the performance of a collective activity as a goal. However, this doesn't mean that each agent has as a self-directed goal that they do something on their own (without the involvement of others). Arguably, agents can also have goals that are "agent-neutral".

The account I have presented is of a kind of joint action that falls somewhere in between robust forms of intentional joint action such as "true collaboration" and "shared cooperative activity" on one side and cases of mere parallel activity such as that exemplified by two strangers walking in parallel on the other side. There are arguably many forms of social coordination and joint action that do not neatly fall into either of these two categories. My hope is that this kind of account can counteract a tendency in both philosophical and scientific discussions about joint action to assume a false dualism between genuinely joint and merely parallel activity. In the beginning of the chapter, I showed how this dualism has structured a debate between Michael Tomasello and Christophe Boesch regarding whether or not chimpanzee group hunting in Taï National Park is a form of joint cooperative hunting. Whether this group hunting behaviour is best explained by the pattern of goals and beliefs specified by the account I have proposed is of course an empirical question that I have largely left be here.

Acknowledgements: This chapter is partly based on research I did during my $\mathrm{PhD}$ studies at the University of Edinburgh, made possible by a European PhD Scholarship from Microsoft Research, for which I am grateful. For fruitful discussions during my PhD, I thank Steve Butterfill, Natalie Gold, Suilin Lavelle, Matt Nudds and Till Vierkant. Further work has been made possible by a postdoctoral research grant (DFF-4089- 00091) from Danish Council for Independent Research and FP7 Marie Curie Actions COFUND under the 7th EU Framework Programme.

\section{References}

Blomberg, Olle. forthcoming. Shared Goals and Development. Philosophical Quarterly. doi:10.1093/pq/pqu059

Boesch, Christophe. 1994. Cooperative Hunting in Wild Chimpanzees. Animal Behaviour 48: 653-67.

Boesch, Christophe. 2002. Cooperative Hunting Roles Among Taï Chimpanzees. Human Nature 13: 27-46.

Boesch, Christophe. 2005. Joint Cooperative Hunting Among Wild Chimpanzees: Taking Natural Observations Seriously. Behavioral and Brain Sciences 28: 692-693.

Boesch, Christophe. 2012. Wild Cultures: A Comparison Between Chimpanzee and Human Cultures. Cambridge: Cambridge University Press.

Boesch, Christophe, and Hedwig Boesch. 1989. Hunting Behavior of Wild Chimpanzees in the Taï National Park. American Journal of Physical Anthropology 78: 547-573.

Bratman, Michael. 1992. Shared Cooperative Activity. The Philosophical Review 101: 327-341.

Bratman, Michael. 2009. Modest Sociality and the Distinctiveness of Intention. Philosophical Studies 144: 149-165.

Brinck, Ingar, and Peter Gärdenfors. 2003. Co-Operation and Communication in Apes and Humans. Mind \& Language 18: 484-501.

Brosnan, Sarah F., Lucie Salwiczek, and Redouan Bshary. 2010. The Interplay of Cognition and Cooperation. Philosophical Transactions of the Royal Society B: Biological Sciences 365: 2699-2710. doi:10.1098/rstb.2010.0154.

Brownell, Celia A., Geetha B. Ramani, and Stephanie Zerwas. 2006. Becoming a Social Partner with Peers: Cooperation and Social Understanding in One- and Two-Year-Olds. Child Development 77: 803-821. doi:10.1111/j.1467-8624.2006.00904.x.

Butterfill, Stephen A., and Ian A. Apperly. 2013. How to Construct a Minimal Theory of Mind. Mind \& Language 28: 606-637.

Butterfill, Stephen. 2012. Joint Action and Development. The Philosophical Quarterly 62: 23-47.

Butterfill, Stephen A. 2013. Interacting Mindreaders. Philosophical Studies 165: 841-863.

Call, Josep, Brian Hare, Malinda Carpenter, and Michael Tomasello. 2004. 'Unwilling' Versus 'Unable': Chimpanzees' Understanding of Human Intentional Action. Developmental Science 7: 488-498.

Call, Josep, and Michael Tomasello. 2008. Does the Chimpanzee Have a Theory of Mind? 30 Years Later. Trends in Cognitive Sciences 12: 187-192. doi:10.1016/j.tics.2008.02.010.

Chalmeau, Raphaël. 1994. Do Chimpanzees Cooperate in a Learning Task? Primates 35: 385-392.

Chalmeau, Raphaël, and Alain Gallo. 1995. Cooperation in Primates: Critical Analysis of Behavioural Criteria. Behavioural Processes 35: $101-111$.

Cohen, Philip R., Hector J. Levesque, and Ira Smith. 1997. On Team Formation. In Contemporary Action Theory Volume 2: Social Action, ed. Ghita Holmström-Hintikka and Raimo Tuomela, 87-114. Synthese Library, Vol. 267. Springer. 
Csibra, Gergely, and György Gergely. 2007. 'Obsessed with Goals': Functions and Mechanisms of Teleological Interpretation of Actions in Humans. Acta Psychologica 124: 60-78.

Gilbert, Margaret. 2009. Shared Intention and Personal Intentions. Philosophical Studies 144: 167-287.

Glüer, Kathrin, and Peter Pagin. 2003. Meaning Theory and Autistic Speakers. Mind and Language 18: 23-51.

Jacob, Pierre. 2012. Sharing and Ascribing Goals. Mind \& Language 27: 200-227.

Kutz, Cristopher. 2000. Acting Together." Philosophy and Phenomenological Research 61: 1-31.

Melis, Alicia P., Brian Hare, and Michael Tomasello. 2006. Chimpanzees Recruit the Best Collaborators. Science 311: $1297-1300$. doi:10.1126/science.1123007.

Miller, Kaarlo, and Raimo Tuomela. 2013. Collective Goals Analyzed. In From Individual to Collective Intentionality: New Essays, ed. Sara Rachel Chant, Frank Hindriks, and Gerhard Preyer, 34-60. Oxford University Press.

Miller, Seumas. 1986. Conventions, Interdependence of Action, and Collective Ends. Nous 20: 117-140.

Miller, Seumas. 2001. Social Action: A Teleological Account. Cambridge University Press.

Naderi, Sz, Ádam Miklósi, Antal Dóka, and Vilmos Csányi. 2001. Co-Operative Interactions Between Blind Persons and Their Dogs. Applied Animal Behaviour Science 74: 59-80.

Pacherie, Elisabeth. 2013. Intentional Joint Agency: Shared Intention Lite. Synthese 190: 1817-1839.

Pacherie, Elisabeth, and Jerome Dokic. 2006. From Mirror Neurons to Joint Actions. Cognitive Systems Research 7: 101-112. doi:10.1016/j.cogsys.2005.11.012.

Perner, Josef, and Johannes Roessler. 2010. Teleology and Causal Understanding in Childrens' Theory of Mind. In Causing Human Action: New Perspectives on the Causal Theory of Action, ed. Jesús H. Aguilar and Andrei A. Buckareff, 199-228. MIT Press.

Petersson, Björn. 2007. Collectivity and Circularity. Journal of Philosophy 104: 138-156.

Petersson, Björn. 2015. "Bratman, Searle, and Simplicity. A Comment on Bratman: Shared Agency, A Planning Theory of Acting Together." Journal of Social Ontology 1.

Petit, Odile, Christine Desportes, and Bernard Thierry. 1992. Differential Probability of 'Coproduction' in Two Species of Macaque (Macaca Tonkeana, M. Mulatta). Ethology 90: 107-120.

Recanati, François. 2007. Content, Mode, and Self-Reference. In John Searle's Philosophy of Language: Force, Meaning, and Mind, ed. Savas L. Tsohatzidis. Cambridge University Press.

Searle, John R. 1983. Intentionality: An Essay in the Philosophy of Mind. Cambridge University Press.

Searle, John R. 1990. Collective Intentions and Actions." In Intentions in Communication, ed. Philip R. Cohen, Jerry Morgan, and Martha E. Pollack, 401-15. MIT Press.

Seed, Amanda, and Josep Call. 2009. Causal Knowledge for Events and Objects in Animals. In Rational Animals, Irrational Humans, ed. Shigeru Watanabe, Aaron P. Blaisdell, Ludwig Huber, and Allan Young, 173-187. Keio University Press.

Sober, Elliott, and David Sloan Wilson. 1998. Unto Others: Evolution and Psychology of Unselfish Behavior. Harvard University Press.

Sterelny, Kim. 2003. Thought in a Hostile World: The Evolution of Human Cognition. Wiley-Blackwell.

Tollefsen, Deborah. 2005. Let's Pretend! Children and Joint Action. Philosophy of the Social Sciences 35: 75-97.

Tomasello, Michael, Malinda Carpenter, Josep Call, Tanya Behne, and Henrike Moll. 2005. Understanding and Sharing Intentions: The Origins of Cultural Cognition. Behavioral and Brain Sciences 28: 675-691.

Tomasello, Michael. 2014. The Ultra-Social Animal. European Journal of Social Psychology 44: 187-194.

Tomasello, Michael, and Katharina Hamann. 2012. Collaboration in Young Children. The Quarterly Journal of Experimental Psychology 65: $1-12$.

Visalberghi, Elisabetta, Benedetta P. Quarantotti, and Flaminia Tranchida. 2000. Solving a Cooperation Task Without Taking into Account the Partner's Behavior: the Case of Capuchin Monkeys (Cebus Apella). Journal of Comparative Psychology 114: 297-301.

Ward, Paul I., and Margit M. Enders. 1985. Conflict and Cooperation in the Group Feeding of the Social Spider Stegodyphus Mimosarum.” Behaviour 94: 167-182. 